DISEASE MARKERS, VOL. 12, 109-115 (1994)

\title{
URINARY $\beta$-HCG IN BENIGN AND MALIGNANT URINARY TRACT DISEASES
}

\author{
A.-B. HALIM*, M. BARAKAT $\$$, A.M. EL-ZAYAT ${ }^{\dagger}$, M. DAW ${ }^{\dagger}$, O. EL-AHMADY* \\ *Tumor Marker Oncology Research Center, Al-A-har University; Cairo, Egypt. \\ \$Bochemical Department. Faculty of Pharmacy; Cairo University; Cairo, Egypt. \\ 'Urology Department, Cairo University, Cairo, Egypt.
}

\begin{abstract}
SUMMARY
Detectable levels of HCG have been reported in conditions other than normal pregnancy, including threatened abortion, ectopic pregnancy, trophoblastic tumors, carcinomas of the stomach, liver, pancreas and breast as well as multiple myeloma and melanoma. The present study was conducted to estimate urinary $\beta$-HCG in bladder cancer and benign urinary tract disorders. 163 individuals were included, 68 with bladder cancer ( 60 males and 8 females), 64 with benign urinary tract diseases ( 55 males and 9 females) and 31 normal healthy controls ( 26 males and 5 females). Urinary $\beta$-HCG was estimated by the ELISA technique using the reagents supplied by DRG International Inc., Germany.

Results of the study revealed an overexpression of $\beta$-HCG in malignant and benign urinary tract diseases. $60.3 \%$ of the cancer patients and $29.7 \%$ of patients with benign diseases showed urinary $\beta$-HCG values above the upper limit of the control group $(2 \mathrm{mIU} / \mathrm{ml})$.
\end{abstract}

KEY WORDs $\quad \beta$-HCG Bladder cancer Benign diseases

\section{INTRODUCTION}

In Egypt, bladder cancer is the commonest type of male malignancy and is second only to breast cancer in females, with a male to female ratio of $5: 1$. The majority of lesions are locally advanced with TNM stages of P1 (3.4\%), P2 (7.4\%), P3 (72.6\%) and P4 (16.4\%); there is a high frequency of squamous cell carcinoma (Khaled, 1993). Different tumor markers have been studied in bladder cancer and different degrees of sensitivity were found (El-Ahmady et al, 1990; Halim et al., 1992; Pohl, 1992; Halim et al., 1993).

Human chorionic gonadotropin (HCG) is a glycoprotein composed of two subunits, $\alpha$ (MW 14500 daltons) and $\beta$ (MW 22000 daltons). The $\alpha$-subunit is identical to that of the three pituitary hormones LH, FSH and TSH while the $\beta$-subunit of HCG ( $\beta$-HCG) is distinct from that of FSH and TSH but shows considerable homology with the $\beta$-subunit of LH over the first $75 \%$ of its amino acid sequence. The carbohydrate content of HCG is variable, but it may account for up to $30^{\circ} \%$ of the molecule (Bagshawe et al., 1979). HCG is normally produced by the trophoblast and can be detected in the blood and urine of pregnant women (Hussa. 1980). It can be detected 5 days after conception and reaches its peak at 8-10 weeks of a normal pregnancy (Daar and Woodruff, 1987).

Correspondence to: Prof. Omar El-Ahmady, Head of Tumor Marker Oncology Research Center, Al-Azhar University, 2-Roushdy St., Safeer Sq., Heliopolis, Cairo, Egypt. Tel. 202 2626655, fax 2022625796 . 
A wide variety of hormone-secreting tumors are known. Hormones produced by tumors are known as eutopic if they are appropriate to the tissue of origin, ectopic if they are not normally associated with the tissue. (Beastall et al., 1991). In trophoblastic tumors, whether of gestational or germ-cell origin, HCG comes closest to being the ideal tumor marker (Daar and Woodruff, 1987). With appropriate cut-off limits, $\beta$-HCG concentrations in serum or urine are elevated in $100 \%$ of cases of choriocarcinoma (De Bustros et al., 1985). Furthermore, the existence of a high risk group makes HCG measurement an appropriate screening test for choriocarcinoma (Beastall et al., 1991). Monitoring of this type of tumors by HCG presents one of the more precise and satisfying features of cancer chemotherapy (Daar and Woodruff, 1987). HCG is well established as a serum marker for germ-cell tumor of the testis (Klein, 1993). It is elevated in 25-76\% of cases of non-seminomatous germ-cell testicular tumors. This figure is improved significantly by the simultaneous measurement of alpha fetoprotein (AFP) and other markers such as lactate dehydrogenase (Daar and Woodruff, 1987 and Beastall et al., 1991). The relapse patterns of patients whose disease recurred following treatment for metastatic germ cell tumors of the testis have been analysed. The analysis shows that routine estimation of serum HCG and AFP is the single most important follow-up procedure (Rathmel et al., 1993). Much lower sensitivity rates (3.6-44.6\%) have been recorded for serum HCG in patients with non-trophobtastic tumors (Daar and Woodruff, 1987).

The present work is an assessment of the diagnostic value of urinary $\beta$-HCG in Egyptian bladder cancer. Some benign urinary tract diseases are included.

\section{MATERIALS AND METHODS}

One hundred and sixty three individuals were included in this study; they were classified into 3 groups:

1- Bladder cancer: $(n=68) ; 59$ were males and 9 were females with age range 28-67 years. Histopathological examination of tumor tissues revealed the following subgroups:

a) Squamous cell carcinoma $(n=42)$, transitional cell carcinoma $(n=23)$, adenocarcinoma $(n=2)$ and undifferentiated carcinoma $(n=1)$.

b) T1 $(n=4), T 2(n=6), T 3(n=36)$ and T4 $(n=22)$.

c) G1 $(n=12), G 2(n=30)$ and G3 $(n=26)$.

2- Benign urinary tract diseases group $(n=64)$; 55 males and 9 females ageing between $20-61$ years. This group included 40 with urinary tract bilharziasis, 8 with benign prostatic hyperplasia, 7 with varicocele and 9 with bladder stones.

3- Normal healthy control group $(n=31) ; 25$ males and 6 females, age range 20-52 years.

All females in the 3 groups were none-pregnant. Twenty four hour urine was collected from each individual and the centrifuged urine samples were stored at $-80^{\circ} \mathrm{C}$ until assayed. Urinary $\beta$-HCG was determined by the ELISA technique using the reagents supplied by DRG International, Germany. The test is based on the principle of a solid phase enzyme-linked immunosorbent assay. A rabbit polyclonal antibody to beta-HCG is coated to a plastic well. Another antibody (murine monoclonal) to $\beta$-HCG conjugated with horseradish peroxidase is used. The urine sample is allowed to react simultaneously with the coated and conjugated antibodies. After incubation and washing to remove the 
Table 1. Urinary $\beta-\mathrm{HCG}$ in the normal, benign and cancer.

\begin{tabular}{lccc}
\hline$\beta$-HCG $(\mathrm{m} \mathrm{IU} / \mathrm{ml})$ & $\begin{array}{c}\text { Normal group } \\
(\mathrm{n}=31)\end{array}$ & $\begin{array}{c}\text { Benign group } \\
(\mathrm{n}=64)\end{array}$ & $\begin{array}{c}\text { Cancer group } \\
(\mathrm{n}=68)\end{array}$ \\
\hline Mean $\pm \mathrm{SE}$ & $1.13 \pm 0.08$ & $* 1.49 \pm 0.15$ & $* * 9.06 \pm 1.94$ \\
Range & $0-2$ & $0-4.8$ & $1-75$ \\
\hline
\end{tabular}

*Significant difference from the control group at $\mathrm{P}<0.05$.

**Significant difference from the control and benign groups at $\mathrm{P}<0.001$.

Table 2. Urinary $\beta$-HCG in squamous cell and transitional cell carcinoma of the bladder.

$\begin{array}{cc}\beta-\mathrm{HCG}(\mathrm{m} \mathrm{IU} / \mathrm{ml}) & \text { Sq. cell carcinoma } \\ (\mathrm{n}=42) & \text { Tr. cell carcinoma }\end{array}$

Mean $\pm \mathrm{SE}$

$8.43 \pm 2.17$

$10.09 \pm 4.09$

Range

$1-75$

$1-72$

unbound material, an enzyme substrate is added and incubated for a certain time to develop a colour. The intensity of the colour is directly proportional to the concentration of $\beta$-HCG in the sample.

\section{RESULTS}

Results of the present study showed marked elevation of urinary $\beta$-HCG in the cancer group compared to either normal control or benign disease group (Table 1). Using the upper limit of the control group as the cut-off value (100\% specificity), urinary $\beta$-HCG showed a sensitivity rate of $60.3 \%(41 / 68)$ in the cancer group and a false positivity of $29.7 \%(19 / 64)$ in the benign group. Only $32.4 \%$ (22/68) of patients with bladder cancer had $\beta$-HCG levels above the upper limit of the benign diseases group. 
Table 3. Urinary $\beta$-HCG in the different stages of bladder cancer

\begin{tabular}{lcccccc}
\hline$\beta$-HCG & $\mathrm{T} 1$ & $\mathrm{~T} 2$ & $\mathrm{~T} 3$ & $\mathrm{~T} 4$ & $\mathrm{~T} 1+2$ & $\mathrm{~T} 3+4$ \\
$(\mathrm{~m} \mathrm{IU} / \mathrm{ml})$ & $(\mathrm{n}=4)$ & $(\mathrm{n}=6)$ & $(\mathrm{n}=36)$ & $(\mathrm{n}=22)$ & $(\mathrm{n}=10)$ & $(\mathrm{n}=58)$ \\
\hline Mean \pm SE & $2.45 \pm 0.43$ & $3.38 \pm 1.07$ & $* 7.60 \pm 2.19$ & $14.24 \pm 4.89$ & $3.01 \pm 0.65$ & $* * 10.1 \pm 2.24$ \\
& & & & & & \\
Range & $1.2-3.5$ & $1-7.6$ & $1.1-66$ & $1.4-75$ & $1-7.6$ & $1.1-75$ \\
\hline
\end{tabular}

*Significant difference from $\mathrm{T} 2$ at $\mathrm{P}<0.05$.

** Significant difference from $\mathrm{T} 1+2$ at $\mathrm{P}<0.005$.

Table 4. Urinary $\beta$-HCG in the different grades of bladder cancer

\begin{tabular}{lccc}
\hline$\beta$-HCG (m IU/ml) & G1 & G2 & G3 \\
& $(\mathrm{n}=12)$ & $(\mathrm{n}=30)$ & $(\mathrm{n}=26)$ \\
\hline Mean \pm SE & $9.86 \pm 5.67$ & $8.02 \pm 2.58$ & $10.09 \pm 3.34$ \\
Range & $1-66$ & $1.2-72$ & $1-75$ \\
\hline
\end{tabular}

Table 5. Urinary $\beta$-HCG in the different benign diseases.

\begin{tabular}{lcccc}
\hline$\beta$-HCG $(\mathrm{m} \mathrm{IU} / \mathrm{ml})$ & Bilharziasis & $\begin{array}{c}\text { Prostatic } \\
\text { hyperplasia } \\
(\mathrm{n}=40)\end{array}$ & $\begin{array}{c}\text { Varicocele } \\
(\mathrm{n}=8)\end{array}$ & Bladder stone \\
& $1.37 \pm 0.17$ & $2.1 \pm 0.58$ & $1.84 \pm 0.54$ & $1.21 \pm 0.37$ \\
Mean \pm SE & $0-3.5$ & $0-4.8$ & $0-3.5$ & $0-2.6$ \\
Range & & & & \\
\hline
\end{tabular}


Table 6. Urinary $\beta$-HCG in males and females of the normal, benign and cancer groups.

\begin{tabular}{lcccccc}
\hline \multirow{2}{*}{$\begin{array}{l}\text { N-HCG } \\
(\mathrm{m} \mathrm{IU} / \mathrm{ml})\end{array}$} & \multicolumn{2}{c}{ Normal group } & \multicolumn{2}{c}{ Benign group } & \multicolumn{2}{c}{ Cancer group } \\
\cline { 2 - 7 } & males & females & males & females & males & females \\
& $(\mathrm{n}=25)$ & $(\mathrm{n}=6)$ & $(\mathrm{n}=55)$ & $(\mathrm{n}=9)$ & $(\mathrm{n}=58)$ & $(\mathrm{n}=10)$ \\
& & & & & & \\
\hline Mean $\pm \mathrm{SE}$ & $1.09 \pm 0.08$ & $1.2 \pm 0.21$ & $1.44 \pm 0.17$ & $1.77 \pm 0.27$ & $9.56 \pm 1.94$ & $14.74 \pm 7.28$ \\
& & & & & & \\
Range & $0-1.5$ & $0.4-2.0$ & $0-4.8$ & $0.8-2.6$ & $1-72$ & $1-75$ \\
\hline
\end{tabular}

Concerning the histopathological classification of bladder cancer, there was no significant difference between the two major types, squamous cell and transitional cell carcinoma (Table 2). Patients with T3 tumors showed markedly elevated $\beta$-HCG compared to those with T2. Patients with advanced cancer $(\mathrm{T} 3+\mathrm{T} 4)$ had higher $\beta-\mathrm{HCG}$ than that patients with early stages $(\mathrm{T} 1+\mathrm{T} 2)$ (Table 3$)$. No marked differences were obtained between the different grades of bladder cancer (Table 4).

There was no marked difference between the different benign disorders included (Table 5) or between males and females of the different investigated groups (Table 6).

\section{DISCUSSION}

The only tumor marker that approaches the ideal is human chorionic gonadotropin in gestational trophoblastic tumors. In this malignancy, the HCG level suggests the diagnosis, staging, response to therapy and prediction of relapse (Bates and Longo, 1985; Lewis, 1993). Although HCG has been found in some patients with various benign diseases including inflammatory bowel disease, duodenal ulcer and cirrhosis (Vaitukaitus et al., 1976), the presence of HCG in plasma of non-pregnant women and men is considered as a biochemical marker of malignancy. (Papapetrou et al., 1980). It was detected in plasma of patients with cancer of stomach $(22 \%)$, liver $(17 \%)$, pancreas (33\%) and adenocarcinoma of the ovary (36\%) (Vaitukaitus, 1977). Data presented by Papapetrou and his colleagues (1980) indicated that measurement of HCG in urine is more efficient than in serum for the assessment of ectopic production of the hormone.

This study revealed the high expression of urinary $\beta$-HCG in patients with bladder cancer compared to those with benign urinary tract diseases and normal healthy controls. $60.3 \%$ of patient with bladder cancer and $29.7 \%$ of patients with benign disease showed urinary $\beta$-HCG above the highest value in the control group. Sensitivity is lower than that recorded for serum HCG in choriocarcinoma and non-seminomatous testicular cancers but higher than in tumors of other origins (Bates and Longo, 1985; Daar and Woodruff, 1987; Poulakis et al., 1991). Because of the false positivity shown in benign urinary tract 
diseases, $\beta$-HCG cannot be used for the differential diagnosis between benign and malignant diseases. In 1990, Botte et al., found that $\beta-\mathrm{HCG}$ in pleural exudates showed a sensitivity of only $9 \%$ at $90 \%$ specificity for discrimination between benign and malignant effusions. On setting the cut-off value as the upper limit of $\beta$-HCG in the benign diseases group, about one third $(32.4 \%)$ of the cancer patients included in the present study can be properly detected. Choice of cut-off value depends on clinical requirements. A test with high sensitivity is required to exclude a strongly suspected diagnosis or to confirm that cancer is not present. A test with high specificity is needed to verify the presence of cancer when there is clinical evidence or when the clinician must be virtually certain of a diagnosis (Pohl, 1992).

Absence of pregnant women in the present study and presence of insignificant difference in urinary $\beta$-HCG between males and females of the 3 investigated groups confirms the ectopic production of the hormone. Some tumors which are associated with moderately high values of HCG show some of the morphological features of the trophoblast (Daar and Woodruff, 1987).

Concerning the histopathological features of bladder tumors, we did not obtain a marked difference between the two major histotypes, squamous cell and transitional cell carcinoma, or between the different grades of the tumors. However, patients with advanced cancer (stages 3 and 4 ) showed higher values of urinary $\beta$-HCG than patients with early cancer (stages 1 and 2). To be of value in prognosis, the tumor marker concentration should correlate closely with tumor size and/or activity, so that a modest elevation means a small localized tumor, whilst a greater elevation suggests bulky disseminated malignancy or an aggressive tumor (Beastall et al., 1991). In all trophoblastic tumors, HCG levels were found to correlate with the bulk of viable tumor (Bates and Longo, 1985). It was stated that no one of the markers including placental alkaline phosphatase, lactate dehydrogenase and $\beta$-HCG performs adequately for the detection of seminoma at initial staging (Munro et al., 1991).

Two types of fragments of the $\beta-\mathrm{HCG}$ were detected in urine of patients with malignancy (Amr et al., 1984). One of these fragments is called $\beta$-HCG core fragment. This fragment was found to have very short plasma half-life, being rapidly cleared from the circulation and thus is more readily detected in urine than serum samples. For this reason it has been called urinary gonadotropin fragment (UGF). It was found that UGF is more sensitive than total $\beta$-HCG in gynecologic tumors (Nam et al., 1990). UGF is recommended as the preferred test also in bladder cancer.

\section{REFERENCES}

Amr, S., Rosa, C., Wehman, R.E., Birken, S., Nisula, B.C. (1984). Unusual molecular forms of HCG in gestational trophoblastic neoplasma. Ann. Endocr., 45, 321-326.

Bagshawe, K.D., Searle, F., Wass, M. (1979). Human chorionic gonadotropin. In: Gray, C.H. and James, V.H.T. (Eds.). Hormones in blood. 3rd edition. Academic Press, London, pp. 364-411.

Bates, S.E., Longo, D.L. (1985). Tumor markers: Value and limitations in the management of cancer patients. Cancer Treat. Rev., 12, 163-207.

Beastall, G.H., Cook, B., Rustin, G.J.S., Jennings, J. (1991). A review of the role of established tumor markers. Ann. Clin. Biochem., 28, 5-18.

Daar, A.S., Woodruff, M. (Eds.). Tumor Markers in clinical practice. Concepts and applications. Blackwell Scientific Publications, Oxford, 1987, pp. 206-225.

De Bustros, A., Baylin, S.B. (1985). Hormone production by tumors: Biological and clinical 
aspects. Clin. Endocr. Metab., 14, 221-256.

El-Ahmady, O., Hamza, S., Aboul-Ela, M., Halim, A.-B., Oehr, P. (1990). The value of tissue polypeptide antigen in Egyptian bladder cancer patients. In: Klapdor, R. (Ed.): Recent results in tumor diagnosis and therapy. W. Zuckschwerdt Verlag München, Bern, Wien, San Francisco, pp. 230-236.

Halim, A.-B., El-Ahmady, O., Hamza, S., Aboul-Ela, M., Oehr, P. (1992). Simultaneous determination of urinary CEA, ferritin and TPA in Egyptian bladder cancer patients. Int. J. Biol. Markers, 7, 234-239.

Halim, A.-B., El-Ahmady, O., Hamza, S., Aboul-Ela, M., Oehr, P. (1993). Serum TPS versus TPA in Egyptian bladder cancer patients. Int. J. Biol. Markers, 8, 221-226.

Hussa, R.O. (1980). Biosynthesis of human chorionic gonadotropin. Endocr. Rev., 1, 268-294.

Khaled, H.M. (1993). Bladder cancer and bilharziasis today. The Cancer J., 6, 65-71.

Klein, E.A. (1993). Tumor markers in testis cancer. Urol. Clin. North. Am., 20, 67-93.

Lewis, J.L. (1993). Diagnosis and management of gestational trophoblastic disease. Cancer Treat. Rev., 71, 1639-1647.

Munro, A.J., Nielsen, O.S., Duncan, W., Sturgeon, J., Gospodarowicz, M.K., Malkin, A., Thomas. G.M., Jewett, M.A. (1991). An assessment of combined tumor markers in patients with seminoma: Placental alkaline phosphatase (PLAP), lactate dehydrogenase (LD) and beta human chorionic gonadotropin (beta HCG). Br. J. Cancer, 64, 537-542.

Nam, J.-H., Cole, L.A., Chambers, J.T., Schwartz, P.E. (1990): Urinary gonadotropin fragment. a new tumor marker. Gynecol. Oncol., 36, 383-390.

Papapetrou, P.D., Sakarelou, N.P., Braouzi, H. and Fessas, P.H. (1980). Ectopic production of human chorionic gonadotropin (HCG) by neoplasma: The value of measurements of immunoreactive HCG in the urine as a screening procedure. Cancer, 45, 2583-2592.

Pohl, A.L. (1992). Multiple testing with cancer markers. In: Sell, S. (Ed.). Serological cancer markers. The Humana Press, Totowa, N.J., pp. 473-494.

Poulakis, N., Sarandakou, A., Rizos, D., Phocas, I., Kontozoglou, T, Polyzogopoulos, D. (1991). Soluble interleukin-2 receptors and other markers in primary lung cancer. Cancer, $\mathbf{6 8}, 1045-$ 1049.

Rathmell, A.J., Brand, I.R., Carey, B.M., Jones, W.G. (1993). Early detection of relapse after treatment for metastatic germ cell tumor of the testis: An exercise in medical audit. Clin. Oncol.. $\mathbf{5}, 34-38$.

Vaitukaitus, J.L., Ross, G.T., Braunstein, G.D., Rayford, P. L. (1976). Gonadotropins and their subunits: Basic and clinical studies. Recent. Prog. Horm. Res., 32, 289-331.

Vaitukaitus, J.L. (1977). Human chorionic gonadotropin. In: Fuchs, F. and Kloppers, A. (Eds.). Endocrinology of pregnancy. Harper and Row, Maryland, pp. 63-75. 


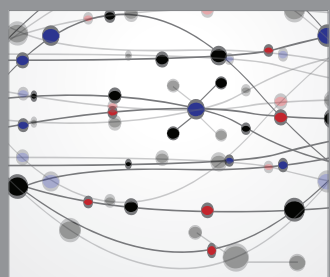

The Scientific World Journal
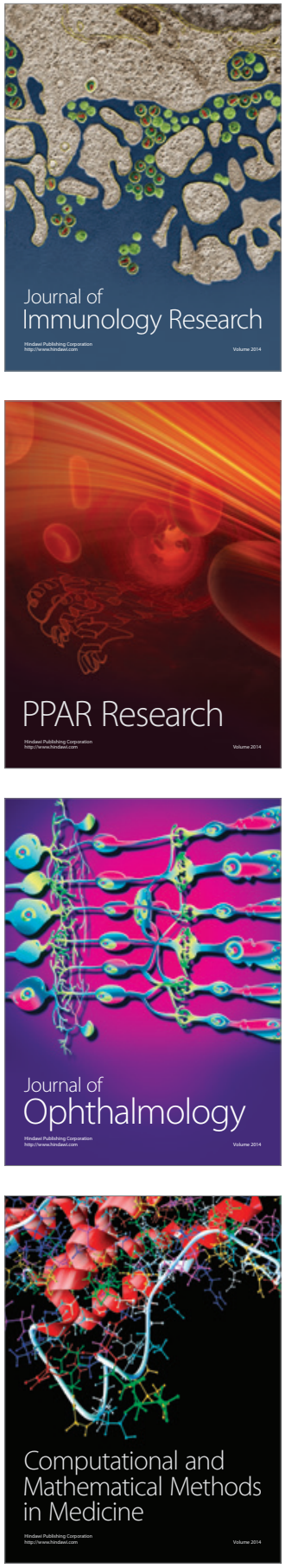

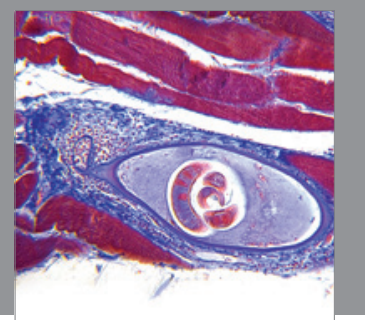

Gastroenterology

Research and Practice
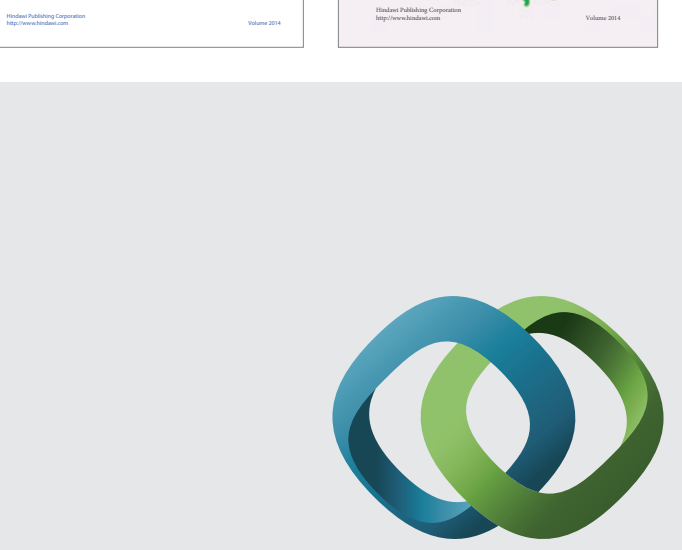

\section{Hindawi}

Submit your manuscripts at

http://www.hindawi.com
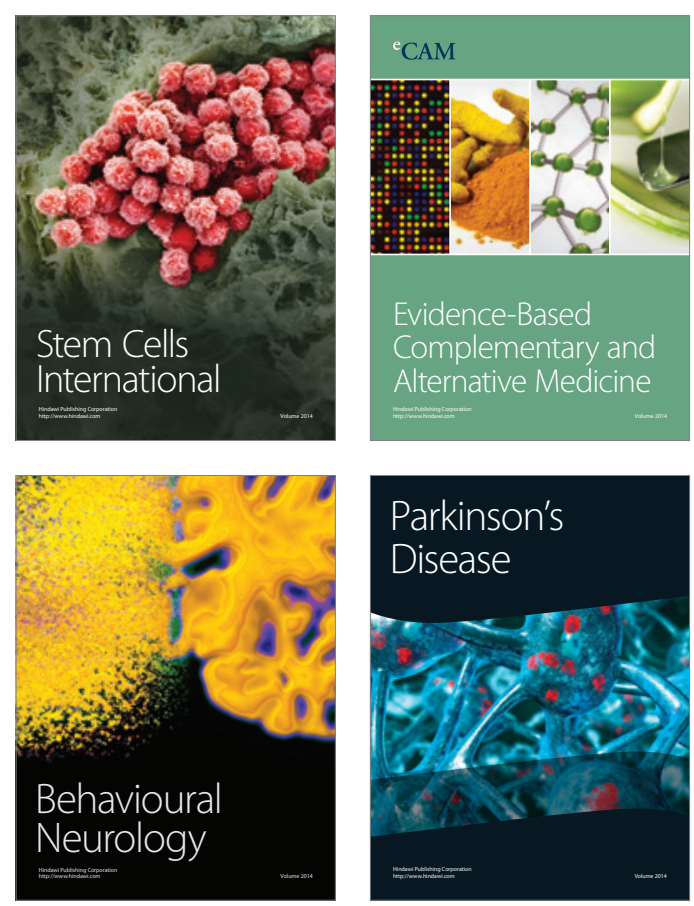

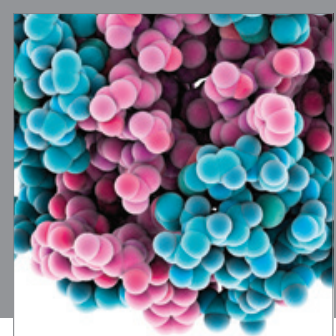

Journal of
Diabetes Research

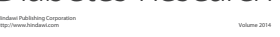

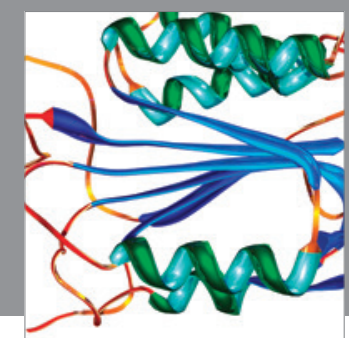

Disease Markers
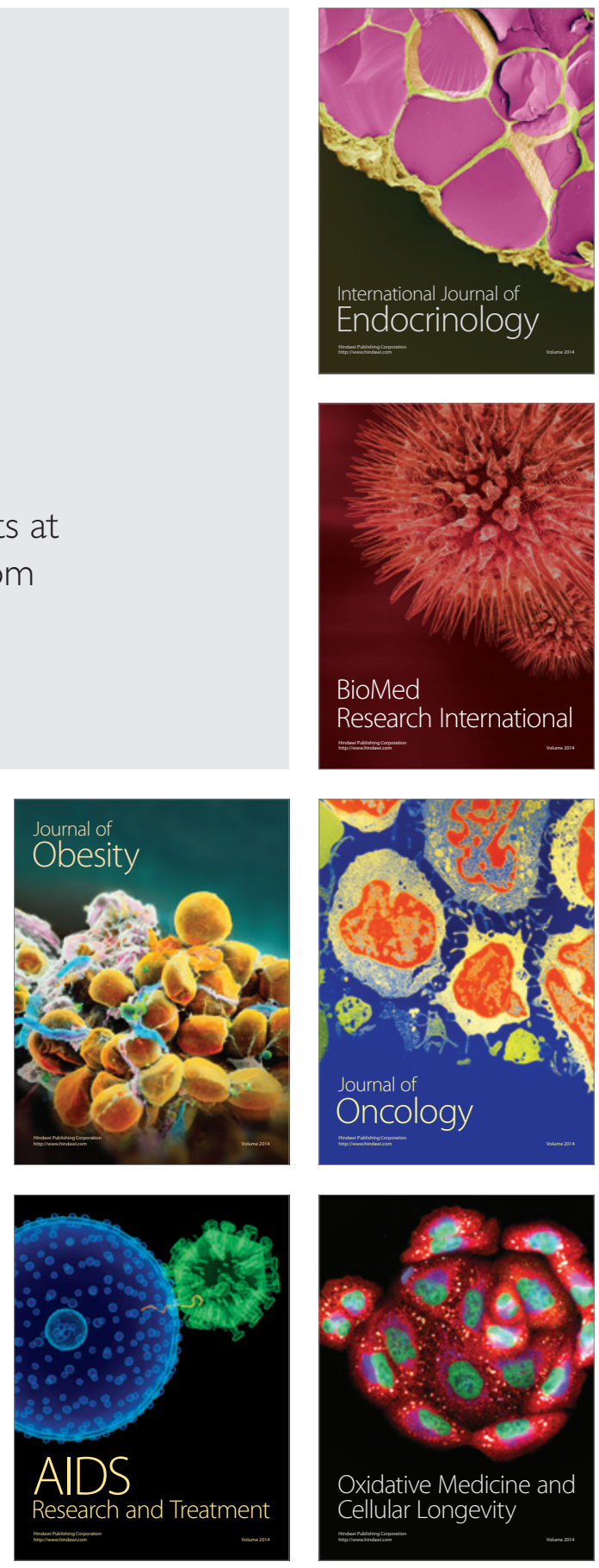